\title{
Development and design of a new single-stage cryogenic modulator for comprehensive two dimensional gas chromatography $(\mathrm{GC} \times \mathrm{GC})$
}

\author{
Ahmed Mostafa $^{\mathrm{a}, \mathrm{b}}$ and Tadeusz Górecki ${ }^{\mathrm{a}}$ \\ ${ }^{a}$ Department of Chemistry, University of Waterloo, 200 University Avenue West, Waterloo, Ontario, \\ N2L 3G1, Canada. \\ ${ }^{b}$ Department of Pharmaceutical Chemistry, College of Clinical Pharmacy, University of Dammam, \\ Dammam, Eastern Province, KSA
}

\section{Supporting information}

\section{Table of contents}

Figure S1: $n$-pentane peak modulation using $100 \mu \mathrm{m}$ I.D. deactivated fused silica capillary showing characteristic chair-shape peak due to breakthrough ( $30 \%$ of peak height). 


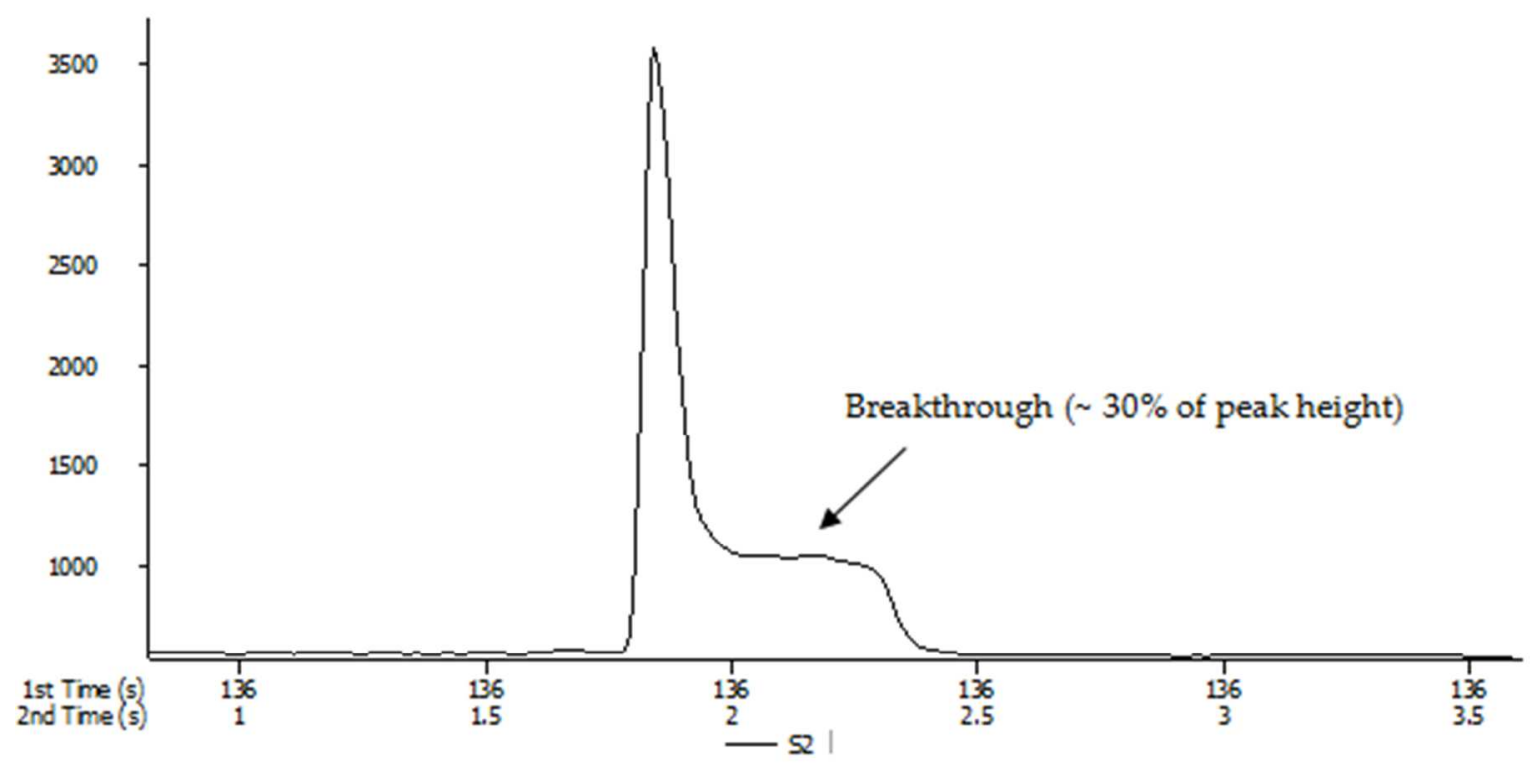

Figure S1: $n$-pentane peak modulation using $100 \mu \mathrm{m}$ I.D. deactivated fused silica capillary showing characteristic chair-shape peak due to breakthrough. 